\title{
Substance Use Disorder Detection Rates Among Providers of General Medical Inpatients
}

\author{
Kristin L. Serowik, $P h D^{1,2}$ (D) , Kimberly A. Yonkers, $M D^{1}$, Kathryn Gilstad-Hayden, $M S^{1,2}$, \\ Ariadna Forray, $\mathrm{MD}^{7}$, Paula Zimbrean, $\mathrm{MD}^{7}$, and Steve Martino, $\mathrm{PhD}^{1,2}$ \\ ${ }^{1}$ Department of Psychiatry, Yale University School of Medicine, 300 George Street, Suite 301, New Haven, CT, USA; ${ }^{2}$ Psychology Service, VA \\ Connecticut Healthcare System, 950 Campbell Avenue, West Haven, CT, USA.
}

BACKGROUND: The prevalence of substance use disorders is higher among medical inpatients than in the general population, placing inpatient providers in a prime position to detect these patients and intervene.

OBJECTIVE: To assess provider detection rates of substance use disorders among medical inpatients and to identify patient characteristics associated with detection. DESIGN: Data drawn from a cluster randomized controlled trial that tested the effectiveness of three distinct implementation strategies for providers to screen patients for substance use disorders and deliver a brief intervention (Clinical Trials.gov: NCT01825057).

PARTICIPANTS: A total of 1076 patients receiving care from 13 general medical inpatient units in a large teaching hospital participated in this study.

MAIN MEASURES: Data sources included patient selfreported questionnaires, a diagnostic interview for substance use disorders, and patient medical records. Provider detection was determined by diagnoses documented in medical records.

KEY RESULTS: Provider detection rates were highest for nicotine use disorder (72.2\%) and lowest for cannabis use disorder (26.4\%). Detection of alcohol use disorder was more likely among male compared to female patients (OR $(95 \% \mathrm{CI})=4.0(1.9,4.8))$. When compared to White patients, alcohol $(\mathrm{OR}(95 \% \mathrm{CI})=0.4(0.2,0.6))$ and opioid $(\mathrm{OR}(95 \% \mathrm{CI})=0.2(0.1,0.7))$ use disorders were less likely to be detected among Black patients, while alcohol (OR $(95 \% \mathrm{CI})=0.3(0.0,2.0))$ and cocaine $(\mathrm{OR}(95 \% \mathrm{CI})=0.3$ $(0.1,0.9))$ use disorders were less likely to be detected among Hispanic patients. Providers were more likely to detect nicotine, alcohol, opioid, and other drug use disorders among patients with higher addiction severity (OR $(95 \%$ CI $)=1.20(1.08-1.34), 1.62$ (1.48, 1.78), 1.46 (1.07, 1.98), 1.38 (1.00, 1.90), respectively).

CONCLUSIONS: Findings indicate patient characteristics, including gender, race, and addiction severity impact rates of provider detection. Instituting formal screening for all substances may increase provider detection and inform treatment decisions.

KEY WORDS: substance use disorder; detection; hospitalization; diagnosis.

$\overline{\text { Prior Presentations These findings were presented at the } 2020 \text { College }}$ on Problems of Drug Dependence (CPDD) Virtual Meeting.

Received April 7, 2020

Accepted October 14, 2020

Published online October 27, 2020
$\mathrm{J}$ Gen Intern Med 36(3):668-75

DOI: $10.1007 / \mathrm{s} 11606-020-06319-7$

(c) Society of General Internal Medicine (This is a U.S. government work and not under copyright protection in the U.S.; foreign copyright protection may apply) 2020

\section{INTRODUCTION}

Substance use disorders (SUDs) are linked to higher rates of hospitalization, greater healthcare costs, and longer inpatient stays. ${ }^{1,2}$ Accurate SUD detection is imperative to identify morbidity and mortality risks and provide optimal treatment. ${ }^{3-6}$ Failure to detect substance use disorders constitutes a missed opportunity for substance use intervention.

The prevalence of SUD is high among general medical inpatients, with rates between 7 and $19.3 \%$ for alcohol use disorder, ${ }^{3,7-12}$ between 5.5 and $11.9 \%$ for illicit drug use disorder, ${ }^{7,8}$ and between 16 and $29.6 \%$ for nicotine use disorder. ${ }^{811,13-15}$ Research suggests that such rates can be explained by co-occurring chronic medical conditions (e.g., diabetes, kidney disease, chronic obstructive pulmonary disease, heart disease, hepatitis $)^{16}$ and are higher than in the general population. ${ }^{7,16,17}$ Medical providers are in a prime position to screen patients for SUD and, when detected, briefly intervene and refer patients to treatment (SBIRT); SBIRT within inpatient medical settings have been found to be efficacious ${ }^{18-21}$ and cost-effective, ${ }^{22}$ including reducing emergency room visits, ${ }^{23}$ rehospitalizations 30 days post-discharge,,$^{23,24}$ and severity of use. ${ }^{24}$

There is considerable variability in the accuracy of inpatient physician SUD detection rates, with rates ranging from 37 to $64 \%$ for alcohol, ${ }^{3,8,9,12,25}$ ranging from 11 to $56.5 \%$ for illicit drugs, ${ }^{8,25}$ and $65 \%$ for nicotine. ${ }^{8}$ Variability appears to be, in part, influenced by study methods used to determine detection accuracy. Specifically, Holt and colleagues ${ }^{25}$ found physician detection rates were higher when assessing only for substance use dependence $(81.3 \%)$ than for both dependence and less severe problematic use (64.3\%). Conversely, another study found detection rates were higher when capturing problematic alcohol use (57.8\%) documented in progress notes, as opposed to a formal alcohol use disorder diagnosis (37\%) in the electronic health record (EHR). ${ }^{9}$ These prior detection studies were limited in that substance use screening measures, rather than "gold standard" independently administered semi-structured diagnostic 
interviews like the Mini-International Neuropsychiatric Inventory (MINI) ${ }^{26}$ served as the reference standard for detection. ${ }^{27}$ Moreover, prior detection studies used DSM-IV ${ }^{28}$ criteria rather than DSM $-5,{ }^{29}$ which no longer distinguishes abuse from dependence and instead characterizes substance use disorders along a continuum of severity level. An updated examination of SUD detection rates using DSM- $5^{29}$ criteria is warranted.

Few studies have assessed which patient characteristics are associated with inpatient provider detection. Being female, ${ }^{30}$ being older, ${ }^{9}$ having higher socioeconomic status (i.e., education, income),${ }^{30}$ exhibiting less severe substance use symptoms, ${ }^{8,25}$ and not having a chronic medical illness ${ }^{31}$ reduce SUD detection among medical inpatients. However, this literature is dated, and other clinical factors, such as health-related quality of life, depression, and motivation, are associated with substance use disorders and their severity ${ }^{32,33}$ and may affect provider detection rates. It is unknown if these factors continue to influence provider detections rates given contemporary use of SBIRT in medical settings, ${ }^{18-20}$ increased prevalence of opioid use disorders, ${ }^{5,6,34}$ and growing legalization of marijuana use at the state level. ${ }^{35}$ Determining correlates of detection rates could identify disparities in SUD detection.

The primary aim of this study was to assess inpatient medical provider SUD detection among patients using hospital billing and EHR review compared to an independent, research-based diagnostic assessment. The study also explored the association of SUD detection with patient demographic and clinical characteristics and the point during hospitalization when initial detection occurs.

\section{METHOD}

\section{Participants}

Participants were recruited for a larger study $(N=1173)$ examining the effectiveness of three distinct implementation strategies to promote medical inpatient provider (physicians, physician assistants, nurses) use of motivational interviewing for their patients with SUDs. ${ }^{36}$ Patient participants received inpatient care on one of 13 general medical units at a large teaching hospital. For the current analysis, inclusion criteria for participants were as follows: being at least 18 years of age, diagnosis of nicotine, alcohol, or illicit drug use disorder as determined by the MINI, ${ }^{26}$ and expected length of stay $\geq 2-3$ days. Ninety-two participants from the parent study did not meet criteria for SUD per the MINI and were excluded from these analyses. An additional five participants were excluded due to missing data on either the diagnostic interview $(N=3)$ or EHR $(N=2)$. The final analytical sample size for this study included 1076 of the 1173 participants from the parent study.

\section{Procedure}

This study was approved by Yale University's institutional review board. After providing written informed consent, participants completed the MINI interview and study questionnaires. Providers were blinded to which of their patients had enrolled in the study. Providers in the parent study were trained on methods to screen patients for use of nicotine, alcohol, and illicit drugs (using the modified CAGE (cut down, annoyed, guilty, eye opener) ${ }^{37}$ and Heaviness of Smoking Inde ${ }^{38}$ ) and how to use a brief motivational interviewing intervention; ${ }^{36}$ they did not learn the MINI. Notably, during the period in which this study occurred, a decision support tool embedded in the EHR alerted physicians to assess their patients for nicotine use upon during the hospital stay and then guided nicotine treatment.

Provider SUD detection was determined in a broad manner. Research staff reviewed participants' EHR for SUD diagnoses documented during the participants' hospitalization. For this secondary analysis, provider detection was defined as any documented SUD in the EHR by any provider (not just study-participating providers), using hospital billing and problem list codes during the hospitalization or within available discharge summaries. For the analyses, diagnoses were coded as either admission or by discharge, depending on whether the diagnosis was documented upon admission or added during the index hospitalization.

\section{Measures}

The MINI, ${ }^{26}$ a semi-structured diagnostic interview that uses DSM- 5 criteria, was used to assess the presence and number of substance use disorders. Age, race/ethnicity, education, and gender were identified through a self-reported demographic questionnaire. Participants also completed Heaviness of Smoking Index ${ }^{38}$ and Addiction Severity Index ${ }^{39}$ to assess severity of substance use. Measures of physical and mental health-related quality of life (SF-12) ${ }^{40}$ and motivation (Motivation to Change Scale $)^{41}$ were also collected via participant self-report. A composite score was created from the average of the three motivation items. Length of stay for the current hospitalization was identified through the EHR.

\section{Statistical Methods}

To examine providers' SUD detection, we compared EHR diagnoses to the reference standard, the MINI, for nicotine, alcohol, cannabis, cocaine, opioid, and other drugs and calculated sensitivity (\# with use disorder who are detected / total \# with use disorder), specificity (\# without use disorder who are correctly classified / \# without use disorder), and accuracy (\# who are correctly classified / total sample) for each SUD. To compare sensitivities (i.e., rate of detection) between SUDs, we conducted $t$ tests for all pairwise comparisons. Association of SUD detection with patient characteristics was tested using bivariate logistic regression for nicotine, alcohol, cannabis, cocaine, opioid, and other drug use disorders in six separate models. Patient characteristics that had a significant or marginally significant bivariate association with detection $(p<0.10)$ were entered into multiple multivariate logistic 
regression models to test their association with detection, independent of other patient characteristics. White was used as the reference when assessing race/ethnicity and female was the reference for gender in the regression models. The Addiction Severity Index was rescaled by multiplying the original scores by 10 to allow for a more meaningful interpretation of the odds ratios. Finally, descriptive statistics were used to illustrate timing of SUD detection.

\section{RESULTS}

Sample demographics and mean scores for each measure are displayed in Table 1. Most patients identified as either White $(55.2 \%)$ or Black $(31.3 \%)$ and over half of the sample was male $(54.5 \%)$. On average, patients were $46.0(\mathrm{SD}=13.7)$ years old, completed 1 year of college, and were hospitalized for 7 days. Most patients had a nicotine use disorder (73.8\%), approximately one-half had an alcohol use disorder, and between 12 and $15 \%$ had cocaine, opioid, or cannabis use disorders.

Table 1 Patient Demographic and Clinical Characteristics

\begin{tabular}{|c|c|c|c|c|}
\hline & Mean (SD) & $\%$ & $N$ & Range \\
\hline Age (years) & $46.0(13.7)$ & & & \\
\hline \multicolumn{5}{|l|}{ Race/ethnicity } \\
\hline White & & $55.2 \%$ & 594 & \\
\hline Black & & $31.3 \%$ & 337 & \\
\hline Hispanic & & $12.6 \%$ & 135 & \\
\hline Other & & $1.0 \%$ & 10 & \\
\hline Male & & $54.5 \%$ & 586 & \\
\hline \multicolumn{5}{|c|}{ Substance use disorder (MINI) } \\
\hline Nicotine & & $73.8 \%$ & 794 & \\
\hline Alcohol & & $50.6 \%$ & 544 & \\
\hline Cannabis & & $15.1 \%$ & 163 & \\
\hline Cocaine & & $12.2 \%$ & 131 & \\
\hline Opioid & & $13.2 \%$ & 142 & \\
\hline Other drug & & $8.4 \%$ & 90 & \\
\hline Education (years) & $12.9(2.3)$ & & & \\
\hline Length of stay (days) & $7.0(7.2)$ & & & \\
\hline $\begin{array}{l}\text { SF-12 Physical Health } \\
\text { Composite }\end{array}$ & 41.5 (12.4) & & & $0-100$ \\
\hline $\begin{array}{l}\text { SF-12 Mental Health } \\
\text { Composite }\end{array}$ & $35.8(11.1)$ & & & $0-100$ \\
\hline Motivation Scale Score & $7.2(2.7)$ & & & $0-10$ \\
\hline $\begin{array}{l}\text { Heaviness of Smoking } \\
\text { Index }\end{array}$ & $2.3(1.6)$ & & & $0-6$ \\
\hline $\begin{array}{l}\text { Addiction Severity } \\
\text { Index-drugs* }\end{array}$ & $0.129(0.131)$ & & & $0-1$ \\
\hline $\begin{array}{l}\text { Addiction Severity } \\
\text { Index-alcohol* }\end{array}$ & $0.204(0.294)$ & & & $0-1$ \\
\hline
\end{tabular}

* Original ASI values, prior to rescaled values used in regression analyses

Short Form Survey (SF-12) scale ranges from 0 to 100 with higher scores indicating better health; Motivation Scale Score was the average of three items that measured importance, ability, and commitment to refrain from using substances; for nicotine models, severity was measured with Heaviness of Smoking Index on a scale ranging from 0 to 6 with higher scores indicating more severe addiction; for alcohol and drug models, severity was measured using Addiction Severity Index (ASI) composite scores, ranging from 0 (no problems) to 1 (severe problems), which were rescaled by multiplying the original scores by 10 to allow for a more meaningful interpretation of the odds ratios; substance use disorder based upon DSM-5 criteria using the MiniInternational Neuropsychiatric Inventory (MINI)
Sensitivity, specificity, and accuracy for all substance use diagnoses at discharge are displayed in Figure 1. Sensitivity (i.e., detection rate) was lowest for cannabis use disorder at $26.4 \%$, which was significantly lower than detection rates of use disorders for nicotine $(72.2 \%, t=-11.9, p<0.001)$, opioids $(65.5 \%, t=-7.4, p<0.001)$, cocaine $(61.1 \%, t=-$ $6.4, p<0.001)$, alcohol $(54.4 \%, t=-6.4, p<0.001)$, and other substances $(51.1 \%, t=-4.0, p<0.001)$. Detection was highest for nicotine use disorder $(72.2 \%)$, which was significantly higher than detection of use disorders for alcohol $(54.4 \%, t=$ $6.8, p<0.001)$, cocaine $(61.1 \%, t=2.6, p=0.010)$, cannabis $(26.4 \%, t=11.9, p<0.001)$, and other drugs $(51.1 \%, t=4.2$, $p<0.001)$. Across substances, rates of specificity were high, with lowest specificity for tobacco $(80 \%)$ and highest for cannabis (94\%). Accuracy analyses indicate that both tobacco and alcohol had the lowest accuracy (74\%), while cocaine had the highest $(89 \%)$.

Results from the univariate logistic regression models are shown in Table 2. The odds of nicotine use disorder detection increased with patient age and addiction severity. Older age, being male, lower mental health scores, greater motivation to change, and greater addiction severity were associated with higher odds of alcohol use disorder detection. The odds of cannabis use disorder detection were associated with higher motivation to change only. Higher physical health scores, greater addiction severity, greater motivation, and longer length of stay were associated with higher odds of opioid use disorder detection. When compared to White patients, Black patients were less likely to be detected for alcohol and opioid use disorders, while Hispanic patients were less likely to be detected for alcohol and cocaine use disorders.

In the multivariable analyses (displayed in Table 3), addiction severity was the only factor significantly associated with nicotine use disorder detection. Race (both Black and Hispanic), addiction severity, motivation, and being male remained significant in the multivariable model for alcohol use disorder, but age and mental health scores did not. In the multivariable model, higher physical health scores, greater addiction severity, and a longer length of stay were each associated with higher odds of opioid use disorder detection. Race was also a significant factor in opioid use detection, with Hispanic patients experiencing lower odds of detection than White patients.

Most initial nicotine, cocaine, and opioid use disorder detection occurred during the index hospitalization, not upon admission (Fig. 2). In contrast, most initial alcohol use disorder detection occurred upon admission, not later during the hospitalization. Cannabis use disorder, when detected, was only detected during the index hospitalization.

\section{DISCUSSION}

This study's findings show that providers' ability to detect SUD, as measured by documentation and billing data, 


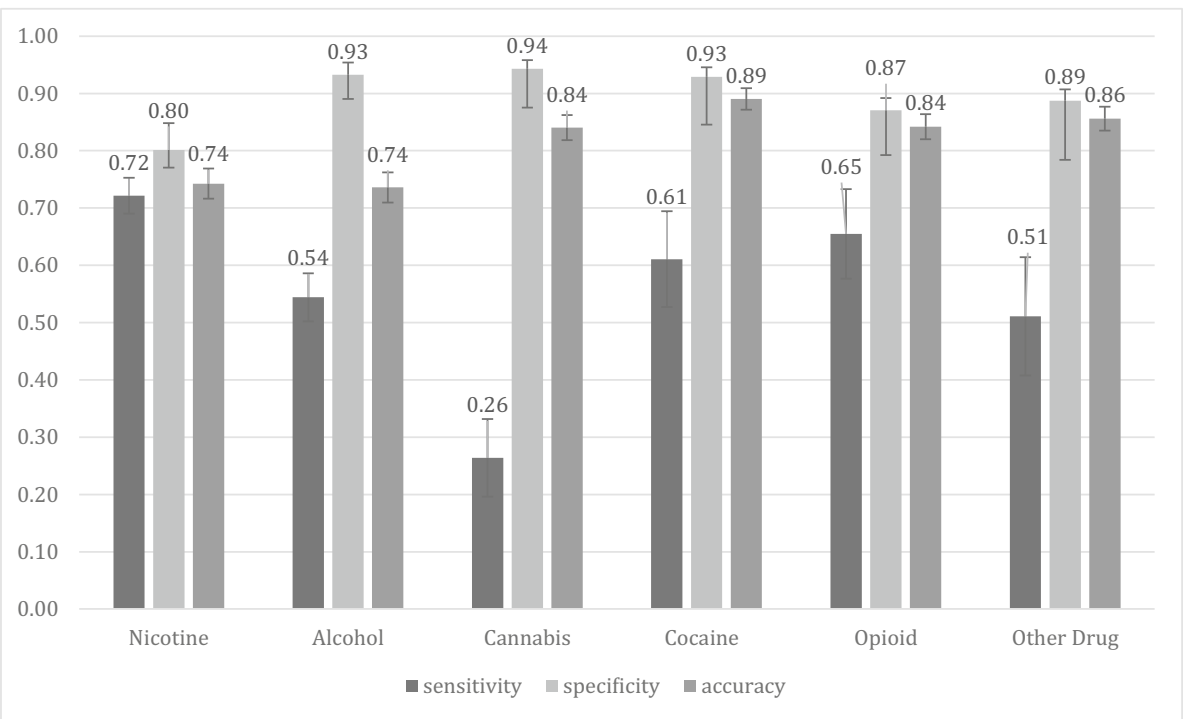

Figure 1 Sensitivity, specificity, and accuracy for provider diagnoses.

varied depending upon the type of substance. The highest rates of detection occurred among patients with nicotine use disorder (72\%), and the lowest rates were for patients with cannabis use disorder (26\%). Rates of detection for alcohol, cocaine, opioids, and other drugs were 54\%, $61 \%, 65 \%$, and $51 \%$, respectively. The findings also reveal that addiction severity most consistently enhanced identification across substance use disorders. Moreover, the majority of substance use disorders were detected during the hospital stay, although approximately twothirds of alcohol use and one-third of opioid use disorder detection occurred upon hospital admission.

Table 2 Results of Bivariate Logistic Regression Models Predicting Odds of Provider Substance Use Disorder Detection

\begin{tabular}{|c|c|c|c|c|c|c|}
\hline & $\begin{array}{l}\text { Nicotine use } \\
\text { disorder } \\
(N=794)\end{array}$ & $\begin{array}{l}\text { Alcohol use } \\
\text { disorder } \\
(N=544)\end{array}$ & $\begin{array}{l}\text { Cannabis use } \\
\text { disorder } \\
(N=161)\end{array}$ & $\begin{array}{l}\text { Cocaine use } \\
\text { disorder } \\
(N=131)\end{array}$ & $\begin{array}{l}\text { Opioid use } \\
\text { disorder } \\
(N=142)\end{array}$ & $\begin{array}{l}\text { Other drug use } \\
\text { disorder } \\
(N=90)\end{array}$ \\
\hline & OR $(95 \%$ CI $)$ & OR $(95 \%$ CI $)$ & OR $(95 \%$ CI $)$ & OR $(95 \%$ CI $)$ & OR $(95 \%$ CI $)$ & OR (95\% CI) \\
\hline Age & $\begin{array}{l}1.01 * \\
(1.00,1.02)\end{array}$ & $\begin{array}{l}1.03 * * * \\
(1.02,1.04)\end{array}$ & $\begin{array}{l}1.00 \\
(0.97,1.02)\end{array}$ & $\begin{array}{l}1.02 \\
(0.99,1.05)\end{array}$ & $\begin{array}{l}0.99 \\
(0.96,1.10)\end{array}$ & $\begin{array}{l}0.98 \\
(0.40,1.01)\end{array}$ \\
\hline Black & $\begin{array}{l}0.79 \\
(0.56,1.11)\end{array}$ & $\begin{array}{l}0.42 * * * \\
(0.29,0.60)\end{array}$ & $\begin{array}{l}0.76 \\
(0.35,1.67)\end{array}$ & $\begin{array}{l}1.12 \\
(0.52,2.40)\end{array}$ & $\begin{array}{l}0.27 * \\
(0.11,0.64)\end{array}$ & $\begin{array}{l}0.66 \\
(0.22,2.00)\end{array}$ \\
\hline Hispanic & $\begin{array}{l}1.04 \\
(0.63,1.72)\end{array}$ & $\begin{array}{l}0.27 * * * \\
(0.14,0.53)\end{array}$ & $\begin{array}{l}0.81 \\
(0.31,2.11)\end{array}$ & $\begin{array}{l}0.26^{*} \\
(0.08,0.92)\end{array}$ & $\begin{array}{l}0.77 \\
(0.26,2.26)\end{array}$ & $\begin{array}{l}0.85 \\
(0.25,2.93)\end{array}$ \\
\hline Other & $0.71(0.13,3.95)$ & $0.27(0.05,1.51)$ & $1.21(0.10,14.16)$ & $0.58(0.03,9.64)$ & & \\
\hline Male & $\begin{array}{l}1.12 \\
(0.82,1.53)\end{array}$ & $\begin{array}{l}3.23 * * * \\
(2.26,4.62)\end{array}$ & $\begin{array}{l}1.13 \\
(0.56,2.30)\end{array}$ & $\begin{array}{l}0.78 \\
(0.38,1.61)\end{array}$ & $\begin{array}{l}1.19 \\
(0.59,2.40)\end{array}$ & $\begin{array}{l}3.01 * \\
(1.27,7.15)\end{array}$ \\
\hline Education & $\begin{array}{l}1.01 \\
(0.94,1.08)\end{array}$ & $\begin{array}{l}1.03 \\
(0.96,1.11)\end{array}$ & $\begin{array}{l}0.98 \\
(0.82,1.17)\end{array}$ & $\begin{array}{l}1.04 \\
(0.87,1.23)\end{array}$ & $\begin{array}{l}0.93(0.79 \\
1.10)\end{array}$ & $0.87(0.71,1.06)$ \\
\hline SF-12 Physical Health & $\begin{array}{l}1.00 \\
(0.99,1.02)\end{array}$ & $\begin{array}{l}1.01 \\
(1.00,1.03)\end{array}$ & $\begin{array}{l}1.00 \\
(0.97,1.03)\end{array}$ & $\begin{array}{l}1.02 \\
(0.99,1.06)\end{array}$ & $\begin{array}{l}1.04 * \\
(1.01,1.08)\end{array}$ & $\begin{array}{l}1.02 \\
(0.99,1.06)\end{array}$ \\
\hline SF-12 Mental Health & $\begin{array}{l}1.00 \\
(0.99,1.02)\end{array}$ & $\begin{array}{l}0.98 * * * \\
(0.96,0.99)\end{array}$ & $\begin{array}{l}1.00 \\
(0.97,1.02)\end{array}$ & $\begin{array}{l}0.99 \\
(0.96,1.03)\end{array}$ & $\begin{array}{l}1.00 \\
(0.96,1.02)\end{array}$ & $\begin{array}{l}1.00 \\
(0.96,1.03)\end{array}$ \\
\hline Motivation & $\begin{array}{l}0.98 \\
(0.92,1.04)\end{array}$ & $\begin{array}{l}1.18 * * * \\
(1.11,1.27)\end{array}$ & $\begin{array}{l}1.20 * * \\
(1.05,1.38)\end{array}$ & $\begin{array}{l}1.07 \\
(0.92,1.26)\end{array}$ & $\begin{array}{l}1.15 * \\
(1.01,1.32)\end{array}$ & $\begin{array}{l}1.03 \\
(0.88,1.22)\end{array}$ \\
\hline Addiction severity & $\begin{array}{l}1.20 * * \\
(1.08,1.33)\end{array}$ & $\begin{array}{l}1.61 * * * \\
(1.48,1.74)\end{array}$ & $\begin{array}{l}1.25 \\
(0.96,1.63)\end{array}$ & $\begin{array}{l}0.91 \\
(0.72,1.15)\end{array}$ & $\begin{array}{l}1.36 * \\
(1.04,1.77)\end{array}$ & $\begin{array}{l}1.29 \\
(0.96,1.73)\end{array}$ \\
\hline Length of stay & $\begin{array}{l}1.03 \\
(1.00,1.06)\end{array}$ & $\begin{array}{l}1.02 \\
(0.99,1.04)\end{array}$ & $\begin{array}{l}1.03 \\
(0.95,1.11)\end{array}$ & $\begin{array}{l}1.02 \\
(0.96,1.07)\end{array}$ & $\begin{array}{l}1.09 * \\
(1.02,1.18)\end{array}$ & $\begin{array}{l}0.99 \\
(0.93,1.07)\end{array}$ \\
\hline $\begin{array}{l}\text { Number of substance } \\
\text { use disorders }\end{array}$ & $\begin{array}{l}0.97 \\
(0.84,1.12)\end{array}$ & $\begin{array}{l}0.96 \\
(0.82,1.12)\end{array}$ & $\begin{array}{l}1.08 \\
(0.81,1.44)\end{array}$ & $\begin{array}{l}1.04 \\
(0.77,1.41)\end{array}$ & $\begin{array}{l}1.15 \\
(0.86,1.53)\end{array}$ & $\begin{array}{l}1.27 \\
(0.93,1.72)\end{array}$ \\
\hline
\end{tabular}

Only variables that were $p<0.1$ in the univariate analyses were included in the multivariate logistic regression analyses (see Table 2) In the table $* p<0.05, * * p<0.01$, ***p $<0.001$

Short Form Survey (SF-12) scale ranges from 0 to 100 with higher scores indicating better health; Motivation Scale Score was the average of three items that measured importance, ability, and commitment to refrain from using substances; for nicotine models, severity was measured with Heaviness of Smoking Index on a scale ranging from 0 to 6 with higher scores indicating more severe addiction; for alcohol and drug models, severity was measured using Addiction Severity Index (ASI) composite scores, ranging from 0 (no problems) to 1 (severe problems), which were rescaled by multiplying the original scores by 10 to allow for a more meaningful interpretation of the odds ratios; substance use disorder based upon DSM-5 criteria using the Mini-International Neuropsychiatric Inventory (MINI) 
Table 3 Results of Multivariate Logistic Regression Models Predicting Odds of Provider Substance Use Disorder Detection

\begin{tabular}{|c|c|c|c|c|c|c|}
\hline & $\begin{array}{l}\text { Nicotine use } \\
\text { disorder } \\
(N=794)\end{array}$ & $\begin{array}{l}\text { Alcohol use } \\
\text { disorder } \\
(N=544)\end{array}$ & $\begin{array}{l}\text { Cannabis use } \\
\text { disorder } \\
(N=161)\end{array}$ & $\begin{array}{l}\text { Cocaine use } \\
\text { disorder } \\
(N=131)\end{array}$ & $\begin{array}{l}\text { Opioid use } \\
\text { disorder } \\
(N=142)\end{array}$ & $\begin{array}{l}\text { Other drug use } \\
\text { disorder } \\
(N=90)\end{array}$ \\
\hline & OR (CI) & OR (CI) & OR (CI) & OR (CI) & OR (CI) & OR (CI) \\
\hline Age & $1.01(1.00,1.02)$ & $1.01(1.00,1.03)$ & - & & & \\
\hline Black & - & $\begin{array}{l}0.37 * * * *(0.23 \\
0.60)\end{array}$ & - & $1.12(0.52,2.40)$ & $\begin{array}{l}\overline{0.23} * *(0.08 \\
0.66)\end{array}$ & - \\
\hline Hispanic & - & $\begin{array}{l}0.26^{* * *}(0.11, \\
0.60)\end{array}$ & - & $\begin{array}{l}0.26^{*}(0.07 \\
0.92)\end{array}$ & $\begin{array}{l}0.98(0.30 \\
3.15)\end{array}$ & - \\
\hline Other & - & $0.28(0.04,2.00)$ & - & $0.58(0.03,9.64)$ & - & \\
\hline Male & - & $\begin{array}{l}3.98 * * * *(1.87 \\
4.77)\end{array}$ & - & - & - & $\overline{3.51 * *(1.41,8.73)}$ \\
\hline Education & - & - & - & - & & - \\
\hline SF-12 Physical Health & - & - & - & - & $\begin{array}{l}1.04 *(1.00, \\
1.08)\end{array}$ & - \\
\hline $\begin{array}{l}\text { SF-12 Mental Health } \\
\text { Motivation }\end{array}$ & - & $\begin{array}{l}1.02(1.00,1.04) \\
1.12 * *(1.03, \\
1.22)\end{array}$ & $\overline{1.19} *(1.03,1.37)$ & - & $\begin{array}{l}\overline{1.14}(0.98, \\
1.33)\end{array}$ & - \\
\hline Addiction severity & $\begin{array}{l}1.20 * * *(1.08, \\
1.34)\end{array}$ & $\begin{array}{l}1.62 * * *(1.48, \\
1.78)\end{array}$ & $1.18(0.90,1.54)$ & - & $\begin{array}{l}1.46^{*}(1.07, \\
1.98)\end{array}$ & $1.38 *(1.00,1.90)$ \\
\hline Length of stay & $1.02(0.99,1.05)$ & - & - & - & $\begin{array}{l}1.13^{*}(1.04, \\
1.24)\end{array}$ & - \\
\hline $\begin{array}{l}\text { Number of substance } \\
\text { use disorders }\end{array}$ & - & - & - & - & - & - \\
\hline
\end{tabular}

Blank cells indicate variables were not included in the multivariate analyses because they did not have a significant or marginally significant ( $p<0.1)$ bivariate association with detection of an SUD in the univariate analyses

In the table $* p<0.05, * * p<0.01, * * * p<0.001$

Short Form Survey (SF-12) scale ranges from 0 to 100 with higher scores indicating better health; Motivation Scale Score was the average of three items that measured importance, ability, and commitment to refrain from using substances; for nicotine models, severity was measured with Heaviness of Smoking Index on a scale ranging from 0 to 6 with higher scores indicating more severe addiction; for alcohol and drug models, severity was measured using Addiction Severity Index (ASI) composite scores, ranging from 0 (no problems) to 1 (severe problems), which were rescaled by multiplying the original scores by 10 to allow for a more meaningful interpretation of the odds ratios; substance use disorder based upon DSM-5 criteria using the Mini-International Neuropsychiatric Inventory (MINI)

Identification of nicotine and alcohol use disorders is comparable to rates found in prior studies, whereas detection rates of illicit substance use disorders were higher. Detection of cannabis use disorders was markedly lower than that of other substance use disorders. Despite efforts to train medical professionals in SBIRT ${ }^{36,42-44}$ and disseminate screening tools publicly on the web,${ }^{45}$ barriers still exist that limit the uniform implementation of screening for substance use in medical settings. ${ }^{46}$ Notably, the hospital where this study was conducted employed a decision support tool in the EHR to cue physicians to assess patients' nicotine use during the hospital stay, very likely driving the higher detection rates. Prior single-site research demonstrates that prompts in the EHR lead to high rates of alcohol and drug use screening ${ }^{47}$ and enhanced

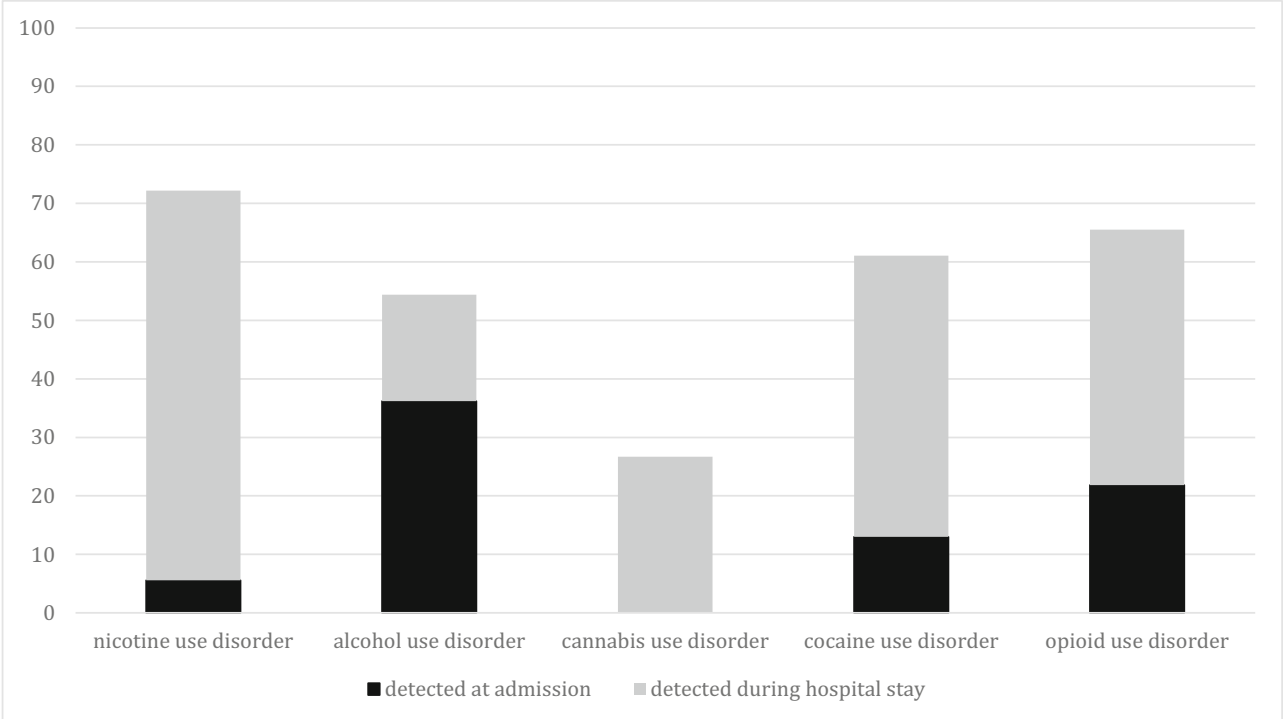

Figure 2 Provider detection at admission and discharge. 
nicotine treatment engagement. ${ }^{48}$ Multi-site pragmatic research is needed to examine if such prompts for substance use screening might similarly lead to improvements in overall detection and concomitant attempts to intervene with appropriate treatments.

The somewhat higher detection rates for illicit drug use disorders in this study, compared to prior studies (51-65\% vs. $11-56 \%),{ }^{8,25}$ are encouraging. In the USA, the opioid epidemic has been driving an increase in medical hospitalizations, ${ }^{49-51}$ and between 2007 and 2017, there has been a concurrent 7.5-fold increase in overdose deaths that involved psychostimulants, often involving opioids. ${ }^{52}$ It may be that inpatient medical providers, like the public, have become more aware of addiction as a public health crisis ${ }^{53}$ and, consequently, are more likely to screen and identify patients with illicit drug use disorders. Nonetheless, a large percentage of patients with illicit drug use disorders still went undetected during their hospitalization, namely cocaine (39\%); opioids (35\%); and other drugs (49\%), suggesting the need to find additional means to improve provider detection of illicit drug use.

One way to increase provider detection is to consider factors that enhance identification. In this cohort, addiction severity was a consistent factor that increased rates of detection across substances, except for cannabis. This finding indicates that providers are identifying patients with significant SUD symptoms but are less likely to detect patients with milder severity, thereby potentially missing opportunities for early detection. As a group, patients in this study sample had at least a moderate level of motivation to reduce or stop their use, suggesting that they might be amenable to brief interventions if detected. Furthermore, the findings of racial disparities in alcohol, cocaine, and opioid use disorder detection are alarming when considering that racial minorities experience more adverse substance-related health and social consequences ${ }^{54-56}$ and barriers to accessing and completing treatment ${ }^{57,58}$ relative to White persons. Universal screening may be one way to minimize the impact of unconscious bias that contributes to racial disparities. ${ }^{59,60}$

Another way to improve SUD detection is through provider training. In the parent study, providers were trained to screen for SUD using the modified $\mathrm{CAGE}^{37}$ and Heaviness of Smoking Index, ${ }^{38}$ but most of the training focused on how to provide the brief intervention. Subsequently, providers engaged in brief interventions with only $8.2 \%$ of their patients. ${ }^{36}$ This low rate may have been due, in part, to insufficient training of providers in how to detect SUD or how to talk with patients about difficult subjects like substance use. ${ }^{61}$ Ongoing supervision and consultation may help foster providers' confidence and willingness to engage in screening procedures for SUD. ${ }^{62-64}$ Training should also target multicultural awareness and provider biases to reduce racial disparities in detection and treatment engagement. ${ }^{57,65}$ Finally, organizational support (e.g., appropriate schedules, caseloads, and incentives) for some members of the inpatient medical team to screen patients for all substances likely would be essential for screening to occur consistently and with sustained proficiency. ${ }^{63,66}$

Notably, time of detection varied by substance, with twothirds of alcohol use disorder and one-third of opioid use disorder detections happening upon admission. Substancerelated medical issues, including alcohol or opioid withdrawal, infections, and injuries, ${ }^{50}$ are frequent presentations seen in emergency departments, ${ }^{67}$ requiring rapid diagnosis and treatment. Early detection of SUD enables more time to address patient treatment needs. A longer length of stay was significantly associated with an increased likelihood that opioid use would be detected during the hospitalization, perhaps giving providers more time to recognize opioid use disorders among their patients experiencing withdrawal, who might not immediately acknowledge this problem given stigmatizing public attitudes toward opioid use. ${ }^{68}$

In contrast, no cases of cannabis use disorder were detected upon admission, and only $26 \%$ were detected by discharge, with severity of cannabis use and length of stay unrelated to detection. The movement to legalize medical and recreational use of marijuana may influence providers' proclivity to screen for problematic cannabis use and detect it, particularly if presenting concerns are not obviously related to the medical conditions being treated. In recent years, public perceptions regarding the detrimental effects of cannabis have decreased, while use of cannabis has increased. ${ }^{69}$ It is unknown if these perceptions may also be true for medical providers, but it might have been a factor in low cannabis use disorder detection. Nevertheless, failure to detect cannabis use disorder is problematic in that cannabis is addictive and can result in biopsychosocial problems. ${ }^{70}$ Regular marijuana use is associated with lowered immune system functioning that increases risk for a variety of medical issues, including stroke and heart disease, ${ }^{71,72}$ chronic obstructive lung disease, ${ }^{73}$ and infectious diseases (e.g., tuberculosis). ${ }^{74}$

This study has limitations. Patients and providers were from a single urban academically affiliated hospital in the Northeast, thereby limiting the generalizability of the findings. Future research should focus on SUD detection in rural and underserved areas and include multiple hospital sites. Moreover, the study procedures did not include searching for substance use that may have been noted in the progress notes. Few prior SUD detection studies included progress notes to determine detection rates. ${ }^{9,12]}$ Some providers may have flagged substance use in progress notes but did not indicate formal diagnoses in hospital procedures, billing coding, problem lists,or discharge summaries. Another limitation is the decision support tool that constrained the study's capacity to estimate providers' independent detection of nicotine use disorders. Finally, the current findings focused on sensitivity analyses rather than specificity or accuracy. Considering the morbidity and mortality, it is clinically very important that medical providers not overlook their patients' SUD (i.e., sensitivity). Fortunately, rates of specificity for SUD were relatively high, indicating providers 
performed well at identifying those who did not have SUD. Nonetheless, rates of sensitivity and specificity could be improved. More research is needed to improve screening procedures to achieve this aim.

In conclusion, this study highlights the need for continued improvement of SUD detection by providers in medical inpatient settings. The implementation of formal screening across substances, prompting providers to assess use, might help. For the large proportion of people without a primary care physician, ${ }^{75}$ inpatient medical hospitalizations are one of few interactions patients have with the healthcare system and potentially the only opportunity to receive SUD screening. Future research should examine whether implementing universal screening procedures improves provider detection of inpatients with SUD and reduces race and gender disparities in SUD detection rates.

Acknowledgments: The authors wish to thank the medical providers at the medical hospital where the parent study was conducted and the research staff (Rebecca Aldi, Monica Canning-Ball, Jessica Katon, Ashley McCaherty, and Jonathan Ryan) for their efforts to obtain the data necessary for these analyses.

Corresponding Author: Kristin L. Serowik, PhD; Psychology Service, VA Connecticut Healthcare System, 950 Campbell Avenue, West Haven, CT 06516, USA (e-mail: kristin.serowik@yale.edu).

Funding This study was supported by National Institute on Drug Abuse (R01 DA034243) awarded to Drs. Martino and Yonkers and by the Interprofessional Advanced Fellowship in Addiction (Office of Academic Affiliations, U.S. Department of Veterans Affairs) awarded to Dr. Serowik.

Data Availability The datasets can be requested through correspondence with the corresponding author and are available upon reasonable request.

\section{Compliance with Ethical Standards:}

This study was approved by Yale University's institutional review board.

Conflict of Interest: The authors declare that they do not have a conflict of interest.

Disclaimer: This manuscript reflects the authors' views and not of the funding agency or the authors' institutional affiliates.

\section{REFERENCES}

1. Gryczynski J, Schwartz RP, O'Grady KE, Restivo L, Mitchell SG, Jaffe JH. Understanding Patterns Of High-Cost Health Care Use Across Different Substance User Groups. Health Aff (Millwood). 2016;35(1):1219.

2. Whiteford HA, Degenhardt L, Rehm J, et al. Global burden of disease attributable to mental and substance use disorders: findings from the Global Burden of Disease Study 2010. Lancet. 2013;382(9904):15751586 .

3. Hearne R, Connolly A, Sheehan J. Alcohol abuse: prevalence and detection in a general hospital. J R Soc Med. 2002;95(2):84-87.

4. Priester MA, Browne T, Iachini A, Clone S, DeHart D, Seay KD Treatment Access Barriers and Disparities Among Individuals with CoOccurring Mental Health and Substance Use Disorders: An Integrative Literature Review. J Subst Abus Treat. 2016;61:47-59.

5. Rudd RA, Aleshire N, Zibbell JE, Gladden RM. Increases in Drug and Opioid Overdose Deaths-United States, 2000-2014. MMWR Morb Mortal Wkly Rep. 2016;64(50-51):1378-1382.
6. Rudd RA, Seth P, David F, Scholl L. Increases in Drug and OpioidInvolved Overdose Deaths - United States, 2010-2015. MMWR Morb Mortal Wkly Rep. 2016;65(50-51):1445-1452.

7. Brown RL, Leonard T, Saunders LA, Papasouliotis $\mathbf{O}$. The prevalence and detection of substance use disorders among inpatients ages 18 to 49: an opportunity for prevention. Prev Med. 1998;27(1):101-110.

8. Kouimtsidis C, Reynolds $\mathbf{M}$, Hunt $\mathbf{M}$, et al. Substance use in the general hospital. Addict Behav. 2003;28(3):483-499.

9. Rumpf HJ, Bohlmann J, Hill A, Hapke U, John U. Physicians' low detection rates of alcohol dependence or abuse: a matter of methodological shortcomings? Gen Hosp Psychiatry. 2001;23(3):133-137.

10. Saitz R, Freedner N, Palfai TP, Horton NJ, Samet JH. The severity of unhealthy alcohol use in hospitalized medical patients. The spectrum is narrow. J Gen Intern Med. 2006;21(4):381-385.

11. Shourie S, Conigrave KM, Proude EM, Haber PS. Detection of and intervention for excessive alcohol and tobacco use among adult hospital in-patients. Drug Alcohol Rev. 2007;26(2):127-133.

12. Smothers BA, Yahr HT. Alcohol use disorder and illicit drug use in admissions to general hospitals in the United States. Am J Addict. 2005; 14(3):256-267.

13. Emmons KM, Goldstein MG. Smokers who are hospitalized: a window of opportunity for cessation interventions. Prev Med. 1992;21(2):262-269.

14. Faseru B, Yeh HW, Ellerbeck EE, Befort C, Richter KP. Prevalence and predictors of tobacco treatment in an academic medical center. Jt Comm J Qual Patient Saf. 2009;35(11):551-557.

15. Srivastava AB, Ramsey AT, McIntosh LD, et al. Tobacco Use Prevalence and Smoking Cessation Pharmacotherapy Prescription Patterns Among Hospitalized Patients by Medical Specialty. Nicotine Tobacco Res. 2019;21(5):631-637.

16. Wu LT, Zhu H, Ghitza UE. Multicomorbidity of chronic diseases and substance use disorders and their association with hospitalization: Results from electronic health records data. Drug Alcohol Depend. 2018;192:316-323.

17. Rockett IR, Putnam SL, Jia H, Chang CF, Smith GS. Unmet substance abuse treatment need, health services utilization, and cost: a populationbased emergency department study. Ann Emerg Med. 2005;45(2):118127.

18. Aldridge A, Linford R, Bray J. Substance use outcomes of patients served by a large US implementation of Screening, Brief Intervention and Referral to Treatment (SBIRT). Addiction. 2017;112 Suppl 2:43-53.

19. Babor TF, Del Boca F, Bray JW. Screening, Brief Intervention and Referral to Treatment: implications of SAMHSA's SBIRT initiative for substance abuse policy and practice. Addiction. 2017;112 Suppl 2:110117.

20. Madras BK, Compton WM, Avula D, Stegbauer T, Stein JB, Clark HW. Screening, brief interventions, referral to treatment (SBIRT) for illicit drug and alcohol use at multiple healthcare sites: comparison at intake and 6 months later. Drug Alcohol Depend. 2009;99(1-3):280-295.

21. McQueen J, Howe TE, Allan L, Mains D, Hardy V. Brief interventions for heavy alcohol users admitted to general hospital wards. Cochrane Database Syst Rev. 2011(8):CD005191.

22. Barbosa C, Cowell A, Bray J, Aldridge A. The Cost-effectiveness of Alcohol Screening, Brief Intervention, and Referral to Treatment (SBIRT) in Emergency and Outpatient Medical Settings. J Subst Abus Treat. 2015;53:1-8

23. Wei J, Defries T, Lozada M, Young N, Huen W, Tulsky J. An inpatient treatment and discharge planning protocol for alcohol dependence: efficacy in reducing 30-day readmissions and emergency department visits. J Gen Intern Med. 2015;30(3):365-370.

24. Wakeman SE, Metlay JP, Chang Y, Herman GE, Rigotti NA. Inpatient Addiction Consultation for Hospitalized Patients Increases PostDischarge Abstinence and Reduces Addiction Severity. J Gen Intern Med. 2017;32(8):909-916.

25. Holt SR, Ramos J, Harma M, et al. Physician detection of unhealthy substance use on inpatient teaching and hospitalist medical services. Am J Drug Alcohol Abuse. 2013;39(2):121-129.

26. Sheehan DV, Lecrubier Y, Sheehan KH, et al. The Mini-International Neuropsychiatric Interview (M.I.N.I.): the development and validation of a structured diagnostic psychiatric interview for DSM-IV and ICD-10. J Clin Psychiatry. 1998;59 Suppl 20:22-33;quiz 34-57.

27. SAMHSA. Examples of Screening and Assessment Tools for Substance Use Disorders. https://ncsacw.samhsa.gov/files/SAFERR_AppendixD. pdf. Accessed Jun 3, 2020.

28. American Psychiatric Association. Diagnostic and Statistical Manual of Mental Disorders: DSM-IV-TR. Washington, DC: American Psychiatric Association; 2000. 
29. American Psychiatric Association. Diagnostic and Statistical Manual of Mental Disorders. 5th Edition. Artlington, VA: American Psychiatric Association; 2013.

30. Moore RD, Bone LR, Geller G, Mamon JA, Stokes EJ, Levine DM. Prevalence, detection, and treatment of alcoholism in hospitalized patients. JAMA. 1989;261(3):403-407.

31. Saitz R, Mulvey KP, Plough A, Samet JH. Physician unawareness of serious substance abuse. Am J Drug Alcohol Abuse. 1997;23(3):343-354

32. Grant BF, Saha TD, Ruan WJ, et al. Epidemiology of DSM-5 Drug Use Disorder: Results From the National Epidemiologic Survey on Alcohol and Related Conditions-III. JAMA Psychiatry 2016;73(1):39-47.

33. Korcha RA, Polcin DL, Bond JC, Lapp WM, Galloway G. Substance use and motivation: a longitudinal perspective. Am J Drug Alcohol Abuse. 2011;37(1):48-53.

34. Martins SS, Sarvet A, Santaella-Tenorio J, Saha T, Grant BF, Hasin DS. Changes in US Lifetime Heroin Use and Heroin Use Disorder: Prevalence From the 2001-2002 to 2012-2013 National Epidemiologic Survey on Alcohol and Related Conditions. JAMA Psychiatry. 2017;74(5):445-455.

35. Monte AA, Zane RD, Heard KJ. The implications of marijuana legalization in Colorado. JAMA. 2015;313(3):241-242.

36. Martino S, Zimbrean P, Forray A, et al. Implementing Motivational Interviewing for Substance Misuse on Medical Inpatient Units: a Randomized Controlled Trial. J Gen Intern Med. 2019;34(11):2520-2529.

37. Brown RL, Rounds LA. Conjoint screening questionnaires for alcohol and other drug abuse: criterion validity in a primary care practice. Wis Med J. 1995

38. Heatherton TF, Kozlowski LT, Frecker RC, Rickert W, Robinson J. Measuring the heaviness of smoking: using self-reported time to the first cigarette of the day and number of cigarettes smoked per day. $\mathrm{Br} \mathrm{J}$ Addict. 1989;84(7):791-799.

39. McLellan AT, Kushner H, Metzger D, et al. The Fifth Edition of the Addiction Severity Index. J Subst Abus Treat. 1992;9(3):199-213.

40. Ware J, Jr., Kosinski M, Keller SD. A 12-Item Short-Form Health Survey: construction of scales and preliminary tests of reliability and validity. Med Care. 1996;34(3):220-233.

41. Miller WR, Johnson WR. A natural language screening measure for motivation to change. Addict Behav. 2008;33(9):1177-1182.

42. Bernstein E, Bernstein $\mathbf{J}$, Feldman $\mathbf{J}$, et al. An evidence based alcoho screening, brief intervention and referral to treatment (SBIRT) curriculum for emergency department (ED) providers improves skills and utilization. Subst Abus. 2007;28(4):79-92.

43. Broyles LM, Kraemer KL, Kengor C, Gordon AJ. A tailored curriculum of alcohol screening, brief intervention, and referral to treatment (SBIRT) for nurses in inpatient settings. J Addict Nurs. 2013;24(3):130-141.

44. Stoner SA, Mikko AT, Carpenter KM. Web-based training for primary care providers on screening, brief intervention, and referral to treatmen (SBIRT) for alcohol, tobacco, and other drugs. J Subst Abus Treat. 2014;47(5):362-370.

45. SAMHSA-HRSA Center for Integrated Health Solutions. Training/other resources. https://www.integration.samhsa.gov/clinical-practice/sbirt/ training-other-resources. Accessed Jan 23, 2020.

46. Vendetti J, Gmyrek A, Damon D, Singh M, McRee B, Del Boca F Screening, brief intervention and referral to treatment (SBIRT): implementation barriers, facilitators and model migration. Addiction. 2017;112:23-33.

47. Johnson JA, Woychek A, Vaughan D, Seale JP. Screening for at-risk alcohol use and drug use in an emergency department: integration of screening questions into electronic triage forms achieves high screening rates. Ann Emerg Med. 2013;62(3):262-266.

48. Bernstein SL, Weiss $\mathbf{J}$, DeWitt $\mathbf{M}$, et al. A randomized trial of decision support for tobacco dependence treatment in an inpatient electronic medical record: clinical results. Implement Sci 2019;14(1):8.

49. Hsu DJ, McCarthy EP, Stevens JP, Mukamal KJ. Hospitalizations, costs and outcomes associated with heroin and prescription opioid overdoses in the United States 2001-12. Addiction. 2017;112(9):1558 1564 .

50. Ronan MV, Herzig SJ. Hospitalizations related to opioid abuse/ dependence and associated serious infections increased sharply, 200212. Health Aff. 2016;35(5):832-837.

51. Wurcel AG, Anderson JE, Chui KK, et al. Increasing infectious endocarditis admissions among young people who inject drugs. Paper presented at: Open forum infectious diseases. 2016.

52. Kariisa M, Scholl L, Wilson N, Seth P, Hoots B. Drug overdose deaths involving cocaine and psychostimulants with abuse potential-United States, 2003-2017. Morb Mortal Wkly Rep. 2019;68(17):388.
53. Woodworth AM, McLellan AT. Converging advances in science, policy and public awareness: A time of great opportunity and change in addiction treatment. Brain Res Bull. 2016;123:110-113.

54. Chartier KG, Hesselbrock MN, Hesselbrock VM. Ethnicity and gender comparisons of health consequences in adults with alcohol dependence. Subst Use Misuse. 2013;48(3):200-210.

55. Mulia N, Ye Y, Greenfield TK, Zemore SE. Disparities in alcohol-related problems among White, Black, and Hispanic Americans. Alcohol Clin Exp Res. 2009;33(4):654-662.

56. Ransome Y, Carty DC, Cogburn CD, Williams DR. Racial disparities in the association between alcohol use disorders and health in black and white women. Biodemography Soc Biol. 2017;63(3):236-252.

57. Guerrero EG, Marsh JC, Khachikian T, Amaro H, Vega WA. Disparities in Latino substance use, service use, and treatment: Implications for culturally and evidence-based interventions under health care reform. Drug Alcohol Depend. 2013;133(3):805-813.

58. Mennis J, Stahler GJ, El Magd SA, Baron DA. How long does it take to complete outpatient substance use disorder treatment? Disparities among Blacks, Hispanics, and Whites in the US. Addict Behav. 2019;93:158-165

59. Burgess DJ, Van Ryn M, Crowley-Matoka M, Malat J. Understanding the provider contribution to race/ethnicity disparities in pain treatment: insights from dual process models of stereotyping. Pain Med. 2006;7(2):119-134.

60. Sabin DJA, Nosek DBA, Greenwald DAG, Rivara DFP. Physicians implicit and explicit attitudes about race by MD race, ethnicity, and gender. J Health Care Poor Underserved. 2009;20(3):896.

61. Wakeman SE, Pham-Kanter G, Donelan K. Attitudes, practices, and preparedness to care for patients with substance use disorder: results from a survey of general internists. Subst Abus. 2016;37(4):635-641.

62. Beidas RS, Edmunds JM, Marcus SC, Kendall PC. Training and consultation to promote implementation of an empirically supported treatment: A randomized trial. Psychiatr Serv. 2012;63(7):660-665.

63. Dorsey S, Pullmann MD, Kerns SE, et al. The juggling act of supervision in community mental health: Implications for supporting evidence-based treatment. Adm Policy Ment Health Ment Health Serv Res. 2017;44(6):838-852.

64. Herschell AD, Kolko DJ, Baumann BL, Davis AC. The role of therapist training in the implementation of psychosocial treatments: A review and critique with recommendations. Clin Psychol Rev. 2010;30(4):448-466.

65. Burgess D, Van Ryn M, Dovidio J, Saha S. Reducing racial bias among health care providers: lessons from social-cognitive psychology. J Gen Intern Med. 2007;22(6):882-887.

66. Aarons GA, Ehrhart MG, Farahnak LR, Sklar M. Aligning leadership across systems and organizations to develop a strategic climate for evidence-based practice implementation. Annu Rev Public Health. $2014 ; 35$.

67. Konstantopoulos WLM, Dreifuss JA, McDermott KA, et al. Identifying patients with problematic drug use in the emergency department: results of a multisite study. Ann Emerg Med. 2014;64(5):516-525.

68. Goodyear K, Haass-Koffler CL, Chavanne D. Opioid use and stigma: The role of gender, language and precipitating events. Drug Alcohol Depend. 2018; 185:339-346.

69. Carliner H, Brown QL, Sarvet AL, Hasin DS. Cannabis use, attitudes, and legal status in the US: a review. Prev Med. 2017;104:13-23.

70. Volkow ND, Baler RD, Compton WM, Weiss SR. Adverse health effects of marijuana use. N Engl J Med. 2014;370(23):2219-2227.

71. Franz CA, Frishman WH. Marijuana use and cardiovascular disease Cardiol Rev. 2016;24(4):158-162.

72. Rumalla K, Reddy AY, Mittal MK. Association of recreational marijuana use with aneurysmal subarachnoid hemorrhage. J Stroke Cerebrovasc Dis. 2016;25(2):452-460.

73. Tan WC, Lo C, Jong A, et al. Marijuana and chronic obstructive lung disease: a population-based study. Cmaj. 2009;180(8):814-820.

74. Gordon AJ, Conley JW, Gordon JM. Medical consequences of marijuana use: a review of current literature. Curr Psychiatry Rep. 2013;15(12):419.

75. Ganguli I, Shi Z, Orav EJ, Rao A, Ray KN, Mehrotra A. Declining use of primary care among commercially insured adults in the United States, 2008-2016. Ann Intern Med. 2020;172(4):240-247.

Publisher's Note: Springer Nature remains neutral with regard to jurisdictional claims in published maps and institutional affiliations. 